\title{
A Necessary Partnership: Study Abroad and Sustainability in Higher Education
}

\author{
Andrea M. W. Dvorak \\ Augsburg College
}

\section{Lars D. Christiansen}

Augsburg College

Nancy L. Fischer

Augsburg College

\section{Joseph B. Underhill}

Augsburg College

\section{Introduction}

The last two decades have seen institutions of higher education put increasing emphasis on both internationalizing their institutions and making them more sustainable (i.e., Society for College and University Planning, 2009; President's Climate Commitment, 2007-2009; NASFA: Association of International Educators, 1998-2009). While laudable in their own right, there are contradictions and tensions between these goals, in particular when we consider the carbon emissions involved in international activities like study abroad. But there is also potential synergy between these goals. In this article, we will explore two case studies of programs abroad that seriously engaged both the contradictions and opportunities inherent in the idea of sustainable international education. The first examines environmental politics and ecology in New Zealand and the Cook Islands and the second compares sustainable urban practices in Canada and the United States. Based on the lessons learned from these case studies, we will argue that partnership between internationalization and sustainability efforts is necessary to help institutions of higher learning become both global and "green." To that effect, we discuss specific and concrete ways to "green" study abroad courses throughout this paper, particularly within the two case studies and in our concluding discussion of strategies for international educators, faculty, and higher education administrators. 


\section{Two Trends in Higher Education: Going Global and Going Green}

With the steady increase in global interconnections, colleges and universities have worked to internationalize their campuses in order to prepare their students to succeed in a world in which the meaning of international boundaries is changing. Infusing the college with international themes or ideas has primarily taken shape in two ways: bringing the world to the classroom (integrating international topics, perspectives, and content into existing curriculum) and bringing the classroom to the world (through study abroad). It is this second aspect of internationalization that we focus on here. Along with the recognition of our growing global interconnectedness, there is an increasing awareness of and concern about higher education's collective impact on the world's ecosystems (i.e., Creighton, 1998; Keniry, 1995). A number of prominent climate change scientists are saying that we need to reduce the level of $\mathrm{CO}_{2}$ in the atmosphere down to 350 parts per million (ppm) to avoid catastrophic and irreversible climate change, but we are already approaching the historically unprecedented level of 400 ppm (Hanson, et al., 2008). The steady increase in resource consumption and the growing alarm about the impact of climate change are leading many sectors of society to explore more sustainable economic and social arrangements. Initiatives by the Association of University Leaders for a Sustainable Future such as the 1990 Talloires Declaration and the American College \& University Presidents' "Climate Commitment" (ACUPCC) (Association of University Leaders for a Sustainable Future, 2008; Presidents' Climate Commitment, 2007-2009) are signs of higher education's interest in engaging meaningfully in environmental issues at the institutional level. Higher education is both part of a global economy that is powered by fossil fuels - what Lewis Mumford called "carboniferous capitalism" (Mumford, 1934) - and is charged with teaching and innovating. As such, colleges and universities have the power - and, we assert, the responsibility - to take a leading role in addressing the problem of climate change. As stated by the ACUPCC, "(n)o other institution in society has the influence, the critical mass and the diversity of skills needed to be successful" in this crucial endeavor (The President's Climate Commitment 2007-2009).

Advocates of these two movements have not seen potential partners in the other cause, partly because each seems to contradict the other. Sustainability advocates on campuses point out that internationalization efforts entail overseas travel which inflate the institution's carbon footprint (Wackernagel and Rees 1996). Outside of providing academic content to study abroad students who major in Environmental Studies, internationalization advocates have seen little connection between their work and sustainability. However, we will argue that 
the connections and areas of synergy between these two trends illustrate that green study abroad is a logical extension of sustainability efforts in higher education. Making study abroad more green allows both movements to become more relevant and to maintain the integrity of their ideals. Green study abroad is a way to reconcile institutional commitments to both sustainability and internationalization of the curriculum; but such reconciliation will take careful planning and possibly institutional policy reform.

\section{Justifying Study Abroad}

The negative effects of climate change raise some difficult moral issues around resource and fossil-fuel consumption, and about the relative worth of different human activities (see Singer, 2004). We do not like to give up things we have become used to-like the ability to travel around the world at relatively low cost-but it appears that we are going to have to start making some of those tough choices. We have become accustomed to burning fossil fuel without thinking about the hidden costs or "externalities" of that activity.

International programs offices encourage students to build understanding and respect the cultures of the world's many people - this is their primary purpose. But study abroad almost always involves air travel, arguably the most fuel-intensive way to move around. For example, a round-trip from New York to London, about 7,000 miles, produces something on the order of 3 tons of $\mathrm{CO}_{2}$ per passenger (Terrapass.com 2010). So far, most international offices have failed to grapple with this conundrum: Carbon use for study abroad has a negative impact on the stability of the earth's climate and, by extension, on the very cultures and peoples it seeks to illuminate. The climate change conundrum is even more difficult for colleges and universities that encourage students to consider the larger impact of certain political, economic, and social choices and structures, but have not turned the same critical eye upon the impact of study abroad. If the aim is for students to gain cultural awareness and understand global social inequities, then institutions must accept some responsibility for contributing to climate change and how it negatively impacts the regions where students and faculty visit.

This issue leads to a more careful examination of the relative costs and benefits of study abroad as educational experience. We can no longer use air travel without taking into account the carbon emissions of that form of travel, and if colleges want to keep providing students with study abroad opportunities, a clear rationale must be articulated for this kind of education. This will be the case as international travel becomes prohibitively expensive (with rising fuel costs), and as the impacts of climate change increase and become more apparent. Many scholars are already beginning to rethink larger 
socio-economic structures in fundamental ways, and study abroad is right in the thick of this — both in terms of its reliance on fossil fuels to provide the required transportation, and in its ability to educate students about alternatives by exposing them to the wide variety of societies, cultures, and economic systems around the world. So where does study abroad fit into the equation?

Finding an answer will involve some difficult discussions about the value of different study abroad programs. We see three possible views on the issue: One is that study abroad is, ipso facto, such a valuable activity that any study abroad is warranted. If we view the impact of climate change as relatively minor compared to the value of study abroad, then we continue with business as usual. This is the current default position of international education since the field has made few (if any) changes to curb its environmental impact. A second perspective is to reflect upon which study abroad programs can be justified, in spite of their potential climate impact. . This would depend on two considerations: the over-all carbon footprint of the program, and the ability of the course content to provide skills and inspire change in students. Such a strategy would involve the difficult task of quantifying and comparing not only academic content, but the value of cultural immersion experiences and of experiencing a location where humans live less carbon-intense lifestyles or where the impact of climate change is so dramatic as to inspire lifestyle changes. Thus, one possible way to prioritize the use of fossil fuels is to ensure that any carbon used now must be used to transition to an economy and society which uses as little fossil fuels as possible. By this logic, only study abroad programs that facilitate this transition would be justified, with students coming out of these experiences with greater awareness, motivation, and skills for helping to bring about change. It would be controversial and thus not easy to compare study abroad programs in this way.

A third perspective is that study abroad is just too consumptive, and it will need to be phased out altogether. In this view, study abroad is a luxury whose benefits do not outweigh the severe costs associated with climate change. Alternatives to study abroad might involve teaching certain content on campus and tapping into local immigrant populations, creating "study away" experiences that provide cultural immersion opportunities. There are some who presently hold this view, and if the predictions of the climate scientists are correct, this may well be where we are heading regardless of what choices we would like to have.

For the time being, we find the second argument most persuasive, since we believe the learning that occurs in study abroad is sufficiently valuable to warrant some burning of fossil fuels. But we do not find it simple or clear cut to weigh the learning experiences (both about climate issues and other valuable 
things students learn) against the implications of programs' carbon footprints. We look to study abroad professionals, and the field of international education as a whole, to consider these issues and help colleges and faculty develop models and strategies for effectively assessing and addressing the overall carbon cost of study abroad.

\section{The Potential Value of Partnership}

Sustainability advocates on college campuses can bring the study abroad office on board and engage them in meaningful conversations about the effect of the carbon footprint of study abroad on the cultures and places they seek to explore and understand. At the same time, sustainability advocates on campus can benefit from the extraordinary educational value of study abroad. Firsthand exposure to issues such as poverty, human rights abuses, or environmental damage has a powerful impact on students. How better to understand the dangers of sea level rise than to study and experience directly the low lying areas of the world, such as in Venice, Shanghai, or the Netherlands? Given an opportunity to have students observe the direct effects of climate change, students will return to campus more likely to lead campus and community sustainability projects. Experiencing well-established public transit systems can be all a student needs to start a carpool, bike, or mass transit project on their campus, and in their home towns and cities. Devotion to make such change can occur as part of the "collateral learning" of the course even if it is on, say, The Art of the Dutch Renaissance rather than expressly concerning environmental subject matter. According to John Dewey, such collateral learning may in fact be the most important component of the course because it contributes to students' engagement as learners in a more general and longterm sense:

Perhaps the greatest of all pedagogical fallacies is the notion that a person learns only the particular thing he is studying at the time. Collateral learning in the way of formation of enduring attitudes ... may be and often is much more important than the spelling lesson or lesson in geography or history that is learned. For these attitudes are fundamentally what count in the future (Dewey, 1938: 48).

Conversely, international programs offices can benefit from sustainability projects on campus. By partnering with sustainability efforts on campus, international offices can highlight their global expertise on subjects like climate change and raise the prospects of both sustainability and internationalization efforts on campus in terms of focus and funding opportunities. In addition, 
students on campus who gain inspiration from high quality sustainable study abroad programs in which they've participated will be excellent recruiters for future study abroad opportunities.

Can thoughtfully-designed study abroad programs deliver on these goals, and, in so doing, justify their large carbon footprint? We turn now to two faculty-led short-term study abroad programs that attempted to address this question. The first was an environmental politics and ecology course studying the biological and political systems in New Zealand and the Cook Islands, and the second an urban sociology course comparing sustainable urban practices in Canada and the United States. In both instances, the challenges and benefits of green study abroad were readily apparent.

\section{Case Study 1: Lessons from the Antipodes}

This study abroad experience entailed two courses offered in New Zealand/Aotearoa (the Maori name for the islands) and the Cook Islands in May and June 2009. Two professors-one from Biology and the other from Political Science-accompanied twenty five Biology, Political Science, and Environmental Studies majors on the month-long program. Students took either an Ecology course or one in Environmental Politics, with the majority of the learning experiences taking place outside traditional classroom settings. The group met with members of Parliament and the Maori community, as well as local farmers, marine biologists, and representatives of the Foreign Ministry, among others. Based on student evaluations and informal feedback during the program, the students found these meetings to be particularly rewarding and educational. Professor Underhill (primary author of this section) and Professor Brian Corner's experiences with this program point to a range of challenges and opportunities in using study abroad as a vehicle for learning about sustainability. Although this particular trip was for biology and environmental studies students, the lessons and opportunities experienced there have relevance to a wide range of study abroad experiences, in both developed and developing countries.

\section{Calculating the carbon footprint}

Perhaps the greatest challenge for this particular study abroad experience was that it required flying quite literally to the other side of the globe. New Zealand is not quite the farthest point on the earth from our college campus, but it is pretty close. This meant that we had to account for a significant carbon footprint, and this is true for the majority of study abroad programs, which involve transoceanic flights. Given the time constraints for these trips (particularly when they are short-term), there is unfortunately no practical 
alternative to air travel for bringing students to these far-flung destinations. Although we might enjoy and prefer a "slow boat to China," with its significantly lower carbon footprint, this is not an option (except for the cruise ship-based programs). In taking the position we do in this article, the point here is not that we give up study abroad because of its high carbon footprint, but rather how we minimize that impact and become accountable for the environmental impact of travel, using it in ways that highlights the importance of shifting our practices away from the current fossil-fuel based system.

For our trip to New Zealand, there were a range of activities and assignments that we carried out in response to this carbon footprint-activities that could be used for virtually any class that requires long-distance air travel. The first was an assignment for students to calculate and track their carbon footprint for the trip. There are two ways to do this: the simpler one is to look just at the resources used and impact caused by the program, while a more complex way is to compare the impact of the program with the impact of group if they had not studied abroad (i.e. their environmental impact in the normal course of their lives). The latter offers greater educational promise, in that it forces students to think about their ongoing environmental impact (and the economic and social structures that shape habits), and facilitates making comparisons between their own community and those they visit.

If using this second, more comparative approach, the first step is to calculate the footprint of a particular student if they did not study abroad (using one of the calculators easily found on websites such as terrapass.org or carbonfootprint.com). Next, calculate the footprint for the program. The air travel constituted the lion's share of our carbon footprint and was the focus of our discussions. For the flight to New Zealand with 29 people we flew 16,000 miles in a Boeing 747-400. The figures per person are as follows: Minneapolis - Los Angeles (round trip) = 2,335 lb. /person; Los Angeles - Auckland (round trip) $=11,000 \mathrm{lb}$. /person. The sobering result of this calculation then is that for each person on the trip, we emitted the equivalent to 13,335 pounds of $\mathrm{CO}^{2}$. By comparison, an average Kenyan produces just 660 pounds for an entire year (one twentieth of what we each produced just on our flight).

The footprint for the rest of trip can likewise be calculated for housing and transportation in country and with ongoing monitoring the students can work on exploring ways to minimize their impact while on the road. This still requires a focus and structure to keep students tracking their fuel consumption while also engaged in the visits, class meetings, and daily logistics of life on the road. Working these assignments directly into the syllabus and daily assignments is important for meaningful discussion of these costs. But one aspect of "paying for" the carbon we emit is to set aside time for keeping track 
of this carbon footprint in the first place. Given that we were travelling with eight people to a van and staying in simple dormitory housing, the students were all actually producing less carbon per person than they would have if living a typical American lifestyle back home-a useful lesson in and of itself. The contrast between transportation during the program and in their normal lives provides a great opportunity for exploring lifestyle choices and their carbon footprints. This is the case for almost any country Americans can visit, as we have one of the highest per capita carbon footprints (about 21 tons per person per year). France, for instance, has per capita emissions of less than 6.5 tons, and in Brazil it is about 2 tons per person. We had ongoing discussions with the students about these contrasts, and the students expressed interest in figuring out ways to compensate for or minimize this overall impact. Our study abroad office, in consultation with the instructors, had already figured in the cost of carbon offsets for the program (a minimal $\$ 75$ per student), and as a follow-up to the course the students decided as a group on how to spend those funds on two different carbon offset programs in New Zealand. We would consider this kind of carbon footprint monitoring, discussion, and offsets as a vital part of any study abroad experience that makes a claim to be green.

\section{Experiencing Climate Change in Aotearoa}

Given the heavy "carbon debt" we were accruing on the program, we felt a great need to make the experience as educationally valuable as possible. The main environmental issues in New Zealand include threats to biodiversity, invasive species, farming practices, and over-fishing (Wallace, 2009). ${ }^{2}$ Perhaps the greatest educational value of visiting Aotearoa, however, is the amazing diversity of unique flora and fauna of the island, which can give students a clear sense of the marvels of the natural world, and of what we stand to lose if the climate continues to change. As many have argued, we need to know what we stand to lose if we want to protect it (Sobel, 1996; Gruenewald, 2008). In trying to inspire a new generation of students to take the challenge of climate change seriously, one of the most important things we can do is show them the beauty, splendor, and value of the natural world that is now gravely threatened by the collective impact of human resource consumption.

Although New Zealand has seen some effects now, and stands to lose a great deal from climate change in the future, many other countries stand to lose much more and are already experiencing some of these effects-from receding glaciers in the Alps to increasing flooding in Venice and the Netherlands, and coral die-off in the Great Barrier Reef. The global and pervasive nature of climate change means that virtually any study abroad program can gain 
something about the impact of this looming global crisis.

The elements of our course that had the most apparent impact on students were the visits we had with people who were most deeply engaged in environmental work (including Cath Wallace, Richard de Hamel, and Jerry $\mathrm{McSweeney)}$ and those whose whole lifestyle and culture reflected dramatically different sets of relationships to the natural world. Simply experiencing the dedication and passion of these individuals provided students with valuable models for civic engagement in their own lives. Although this kind of exposure is by no means limited to New Zealand, there is a very strong commitment to environmentalism there (it being, along with Tasmania, the birthplace of the Green Party).

Another way to green study abroad experiences is by visiting some of the "brownest" places such as Australia, China and parts of Eastern Europe and the former Soviet Republics. In this course, students gained great insights from visiting a large open-pit coal mining operation on the West Coast of the South Island. It highlighted both the New Zealand commitment to habitat and biodiversity protection, and the real challenges associated with the fossil-fuel economy. The huge challenges accompanying large-scale mining and other similar enterprises provided students with valuable insights into the workings of the "carboniferous capitalism."

It was also illuminating to observe the dramatically different agricultural systems in New Zealand, in which the huge population of sheep and cattle are raised almost entirely in open pastures and grasslands, instead of in the Concentrated Animal Feeding Operations (CAFOs) prevalent in the US (Pollan, 2006). Instead of growing millions of acres of corn as feed for their livestock, the Kiwi farmers provide sufficient pasture land for their herds, and prevent over-grazing through careful land management practices. This points to the value of selecting destinations for study abroad where students can gain exposure to more environmentally friendly and sustainable economic and social systems. Destinations as diverse as Denmark, Brazil, and Japan all offer chances for students to get exposure to economic systems that are less resourceintensive.

\section{A Maori Understanding of Sustainable Development}

One of the great values of study abroad is the potential for cultural encounters that open students up to new ways of viewing the world. One way that cultures differ is in their relationship to the natural world, and one goal of green study abroad should be to include conversations with communities that have developed more harmonious forms of coexistence with the natural world (Bowers, 1997). In the category of cultural encounters, two of our visits were 
of particular note: our meeting with members of the Maori community in Rotorua and their work on a new green housing projects (an Eco-papakainga), and our meeting with an elder and educator on the Cook Islands who showed the students how to prepare and cook a meal that was made completely with local and native materials and ingredients. Both visits forced students to rethink the basic values and consumption patterns of their lives.

The meeting with the Maori community organizers, Tess Kora and Waereti Tait, provided an example of a project that was based very solidly in the culture and social structure of the local Marae (Maori tribal community), that embraced notions of sustainability and environmental justice. The project involved building a communal housing complex to provide homes for community members who had previously been living in "chronically substandard" and sometimes illegal self-built shelters. A number of the houses had no running water, electricity, or sewer connection. The eco-project was based, first and foremost, in the extended family structure (the whanua) and cultural traditions that are passed along inter-generationally. The project also drew on Maori conceptions of the intimate and fundamental connection between the people and the land. Their conception of Manaakibia a Papatuanuku holds that healing the land and healing a people are one and the same. The project thoroughly integrated social issues, environmental sustainability, health, and culture in an impressively holistic manner. This visit provided students with an entirely different way of conceiving of humanity's relationship with the natural world, and an example of a "development" project that was truly based in the local community rather than imposed from outside. Other study abroad programs that have the opportunity to visit with and learn from local and indigenous communities would do well to provide these opportunities to their students, while remaining aware and sensitive to the needs and sensibilities of these communities.

\section{Eating Locally on an Island in the middle of the Pacific Ocean}

During the course, we spent a few days on the Cook Islands, examining the impact of climate change, coral reef ecology, and sustainable practices on an island (Rarotonga) that is a mere five miles across. The island nation was an excellent place for students to gain a greater appreciation for the threat of rising sea levels, and the impact of climate change on the coral reefs. A highlight of our stay there was a traditional Pacific-islander meal prepared by local residents. It began with a fire ceremony, in which an elder involved the students in gathering the necessary materials (mostly various parts of the coconut tree) and then starting the fire literally by rubbing two sticks together. Students learned of the traditions and history associated with the fire-making 
and social networks on the islands. The fire was then used to cook the various dishes — chicken, taro, squid, potatoes and kumara - all baked and eaten in "dishes" made from banana leaves. The meal itself was the most "local" and low impact meal any of us had eaten. Virtually all the ingredients for the meal were gathered within a few hundred yards of the beach. Taro root and leaves from the garden across the road, chickens raised nearby, a squid caught in the reef 50 feet from where we sat, and some tuna caught a little further off shore. The meal demonstrated how to eat with virtually no carbon footprint and as part of a local community. Students got the concept of how to live very, very simply. This points to the value of providing students with alternatives to the highly consumptive and carbon-intensive lifestyle to which they are so accustomed. Finding other such encounters around the globe is another way to work toward greener study abroad, while also pursuing the goal of globalizing higher education. Catching, killing and gathering food and making one's own dishes may be beyond the scope of most study abroad courses, but there are ample opportunities to eat locally produced food all over the world.

\section{Bringing the lessons home}

These experiences, taken together helped to inspire students to take a number of environmental initiatives upon their return. One student undertook a summer research project on using algae as a source for biofuels; one arranged to meet with the mayor of Minneapolis to discuss urban greening projects; one is pursuing ways to reduce the level of waste in the campus chemistry program; and others have pursued ideas such as implementing a regular carbon offset fee for all our study abroad programs. We cannot be sure that this study abroad experience directly prompted these actions, but it seems plausible to think that it helped inspire the students in some way.

\section{Case Study 2: "Sustainable Cities in North America"}

"Sustainable Cities in North America," taught by Professors Christiansen and Fischer, was run in July 2008 and July 2010. In both iterations, we (Christiansen and Fischer, primary authors of this section) brought twelve students to Vancouver, British Columbia for two weeks, and Portland, Oregon for ten days, and then returned to Minneapolis for the final week of the course. The purpose of the course was to learn about the multiple dimensions of urban sustainability and their complex interrelations; to develop students' powers of "urban literacy" (the ability to "read" a city by understanding its planning and design elements); and to enact practices back in the Twin Cities and our home campus based on what we learned in our comparison of the three cities.

Our course was unique in many ways, including those practices that 
helped make the course as green"as possible. These included our method of travel within and between the west coast cities, recycling, consuming only what was necessary, and being selective about our food and accommodation choices. Because we focused explicitly on urban environmental sustainability, the readings, speakers and site visits contributed to its green emphasis. While these latter elements (readings, etc.) are most appropriate for courses where sustainability is the course theme, we believe that the former elements (alternative transportation, etc.) are possible actions for study abroad courses on any theme or topic. Because this paper is focused on the challenges of sustainable study abroad, we highlight these elements.

While our desire was to teach this course in a way that was consistent with what we were learning by designing it on the principles of "Leave No Trace" -- a camping principle that our class applied in a serious way to urban contexts -- there were still aspects of the course that contradicted our goal of teaching a green course. For example, we decided that, given our time constraints, to fly to the Pacific Northwest, even though we could have taken Amtrak. For the next iteration of this class, we are reconsidering the Amtrak option as it may be more feasible than we originally imagined. Nevertheless, in a course on urban sustainability such limitations still serves our teaching goals. For our purposes here, insights on such limitations will serve to illuminate the challenges that study abroad courses face in order to develop new strategies for addressing them.

\section{Food Choices: Our month of eating locally}

Clearly an essential experience of unfamiliar cultures centers on cuisine. This is an area of the study abroad experience where there is ample opportunity to enact green practices. Inspired by "The Year of Eating Locally" from Bill McKibben's Deep Economy (McKibben, 2007), we encouraged our students to eat as locally as possible during the month-long course. This meant eating at local restaurants rather than national or global chains, eating at restaurants with explicit sustainability missions, finding meals at farmers markets, and cooking our own meals using ingredients from farmers markets and local grocers. This last practice - cooking our own meals - required that our lodging amenities include at least partial kitchens. We can imagine that access to kitchens and cooking utensils may be a possibility in study abroad courses on any topic and in many countries, both in the "developed" and "developing" worlds.

Eating locally not only reduced our carbon impact, but had cultural benefits as well. It gave our students new ways to interact with residents at favorite local spots. Purchasing food at farmers markets provided our students with a more specific and nuanced understanding of what is locally raised and 
who is producing that food. And, as McKibben points out, farmers markets provide the conditions for conversations to occur; they are public spaces that enhance social capital in ways that students can learn more about their host culture. Eating locally, particularly based on shopping at markets and grocers, felt more like a residential (as opposed to a tourist) experience. Our students, armed with their own re-usable canvas bags and refillable water bottles, blended in with locals. Here, a green practice also improves the chance for students to have strong cultural immersion experiences, which is equally relevant for courses in the arts, humanities, and even natural sciences. For example, given the centrality of both the kinds of food and methods of food preparation that are unique to a culture, having students create meals of the host culture are opportunities to advance understanding of a culture's art, history, agricultural systems, and the like, as well as providing opportunities to practice language use.

\section{Lodging: Density and green buildings}

One of the major limitations to green study abroad is typically the hospitality industry, known for its wasteful use of water for cleaning linens and towels (among other problematic practices). Instead of staying in hotels, we stayed in dorms at Portland State University (PSU) and UBC, and used that as an opportunity to discuss the environmental advantages of dense living arrangements. In Portland, we stayed at PSU's LEED-certified dorm, Epler Hall. The first LEED-certified building in all of Portland, Epler Hall is loaded with innovative features designed for energy efficiency that PSU's sustainability coordinator highlighted for us.

Intentionally green buildings are great lodging choices in a study-abroad context. But many places have no such designated buildings. Yet, homes that are energy efficient need not have the bells and whistles of contemporary green technology and architecture. We can imagine homes (say, where study abroad students are doing home stays) that are enacting green practices out of necessity and tradition. The recycling of water, use of grey water for multiple purposes, and efficient use of heat for both cooking and heating a home, are all practices that can be found in living quarters of many people throughout the world (such as the Maori, but also Denmark, Italy, and Germany) though they may not be identified as green per se. Even in courses where the emphasis is not explicitly environmental, it may still be useful to highlight cultural differences in water and energy consumption as an opportunity to discuss how this relates to differences in pricing systems (on gas, utilities, etc) and political systems (which regulate usage). The hope is that this will introduce students to cultivating a less wasteful lifestyle. 


\section{Transportation: The green choices model}

We found that the limits of green study abroad are found principally in the manner by which the group travels to its destination. In both iterations of the course, we chose to fly to and from the west coast. Our justification was primarily the issue of time. We believed that had time permitted, and if Amtrak's service were not so uneven and unpredictable (for political-economic reasons that we discussed in our course), we would have taken the train to get to Portland (and back to the Twin Cities). It takes over two days to travel from Minneapolis to Portland by train. We also justified air-travel on the basis that there are too few sleeper cars on Amtrak to accommodate group travel. Thus, we utilized air-travel, releasing enormous amounts of $\mathrm{CO}_{2}$ (estimated at 850 pounds per person, or around 12,000 pounds total) through the burning of jet fuel.

One solution that some faculty and campus abroad programs are employing to address air travel and the $\mathrm{CO}_{2}$ that it releases is to purchase carbon offsets. This is a problematic idea for a host of reasons (discussed below). Another solution, one that our students developed, was to reduce their own energy consumption equivalent to the amount of $\mathrm{CO}_{2}$ produced in flying, once back at home. Indeed our students have made this commitment.

After the second run of our course, we believe that the best solution is to avoid air-travel altogether by taking Amtrak to the Western U.S. and Canada, and utilize time on the train to accomplish some of the pre-departure course discussions. Our course shows that there is a clear advantage for continentally based study abroad courses that at least provide the possibility of non-air flight transportation to destinations. When we discussed the problems of air travel with our students, they felt strongly that the longer time required on the train could still be used to good effect (for reading, writing, and even lecture and discussion) and would illustrate the purpose of the course from the opening moments. The problem of lack of sleeping cars would not be an issue, they have assured us, because Amtrak seats are long (compared to air or bus travel) and it is possible to sleep without a sleeper car.

For almost all study abroad courses - particularly those involving crossoceanic travel - the use of air travel seems unavoidable and alternatives seem inconceivable. But perhaps taking ships abroad can present opportunities that are overlooked because the option is rarely if ever considered. For example, those who teach history could make good use of the experience for referring to pre-twentieth century travel experiences and even highlight how time was experienced differently for people of the past. We can imagine other aesthetic and experiential opportunities with maritime travel as well. Still, it would take significantly longer to cross the ocean on a boat than plane, and consequently 
such cross-oceanic travel would likely make the most sense for those courses that are longer in duration, such as a semester-abroad or a year abroad.

Obviously, the problem of air-travel is a serious challenge, if not the key challenge, that deserves creative thinking in terms of its justification for the other benefits that travel-abroad provides.

Often the transportation of students to sites in the field involves a van or tour bus. The use of a van or tour bus is, from an environmental standpoint, a mixed bag. On the upside, the tour bus is more fuel efficient per passenger than cars or taxis; in this way it is no different than taking a city bus. On the downside, there are three problems with the van/tour bus: First, they use fossil fuels, whereas some city bus systems have electric, hybrid or bio-diesel buses (Vancouver's bus system largely runs on hydroelectric power). Second, it creates a singularity of experience; this is especially the case when sitebased tour guides are hired to bring classes to various sites. Third, hired buses separate the group from the culture they could be experiencing and can limit their cultural interactions.

We gave our students choices of how to get around within both cities. Professor Fischer led students using mass-transit and walking, and Professor Christiansen led students using bicycles. We call this model the "green transportation choices" model because these methods of getting from point A to point $\mathrm{B}$ have the least impact on the environment. Multiple choices were crucial for students because they had different kinds of experiences based on how they got around, and because their multiple experiences of place translated into different lifestyle possibilities back home. Multiple choices also make study abroad programs like ours accessible to students with physical disabilities.

In "Sustainable Cities," we secured bicycles through local bicycle rental shops. This was a simple and easy process, though to be safe we reserved group rentals in advance. In many cities throughout the world the renting of bicycles is a viable option. Moreover, as bicycle sharing systems become popular, particularly in many French cities (with Paris's 20,000 bicycle Velib system being the largest in the world), the use of bicycles is an increasingly easy choice. For those relying on public transportation, we found obtaining daily or weekly passes simple and required no advanced planning. Our transportation decisions provided us with notable advantages. We sought to have as little polluting impact on the local environment as possible, and our hosts and guest speakers expressed their appreciation for our willingness to get around under our own or public power. This was also healthier and more active than the conventional practice of riding everywhere together in a van. Because food is fuel for bicycling and walking, our fuel came from locally based food 
producers and distributors, thereby allowing us to demonstrate to our students the interrelations between food, fuel, and transportation systems.

An unanticipated advantage of our green transportation choices model was the rapid development of a sense of confidence and independence among our students. This advantage cannot be understated. Our students experienced neighborhoods, parks, architecture, public spaces, (etc.) at the pace of bicycling, walking, and mass-transit, allowing them to interact more directly with people in those places. Bicycling, transit and walking allowed each of us to get to know each city much better and in more detail than we would within a car, van, or tour bus. Our students quickly became familiar with local transit schedules, street layouts, and neighborhoods. Their map reading skills improved as well. We would argue that these modes of transportation enhanced our students' observational powers. Moreover, it helped our students to be less dependent on us as "tour guides." Within 24-48 hours of arrival, students did not need to ask us how to get around; they knew they were expected to figure it out and that they were capable of doing it. This also meant that during free time, they took it upon themselves to organize their own excursions with their newfound local knowledge. In other types of abroad courses, transportation to the theater or music venues (for fine arts courses), or to sites of historic importance (for history courses), or to scientific laboratories (for science courses), and so forth, can be achieved with use of non-motorized, active transportation.

There are only two drawbacks to our "green transportation choices" model: First, relying on public transit and walking means that course participants must pack lightly, and use luggage that preferably has wheels. On our travel days, we found ourselves walking with luggage to public transit, and as such, the heavier the suitcase, the more physically challenging the transport. Second, the distance of our excursions was limited by public transit and the time and energy it would take to bicycle longer distances. Nevertheless, we found both of these limitations to be of so little trouble as to be practically insignificant.

\section{Enacting change at home}

Once the course was completed, our students embarked upon several action projects, some personal, others collective. Many of our students reported making changes in personal habits, primarily eating more local food and using means of transportation other than automobiles. More ambitious were collective actions. Three of the students worked with Augsburg faculty, administrators, and our food service provider to institutionalize composting at Augsburg. This took the full academic year following the course to accomplish, but they were successful. During the summer following the first iteration our course (2009), one of our students led a group of three other bicyclists on a 
highly publicized "reconnaissance mission" bicycle ride from Minneapolis to Portland. These "Pedalers for Progress" gained the support of local and federal policy makers, notably Senator Amy Klobuchar, to ride to Portland and meet with transportation policy advocates and policy makers there to share ideas and bring them back home. Finally, two of our students, with the support of other students as well as Augsburg faculty and administrators, organized a series of activities for the opening month of the 2009-2010 academic year called "Sustainability Awareness Month." This month was intended to help new (and returning) students to institutionalize new, green practices around campus. Our course, "Sustainable Cities in North America," was undoubtedly a causal factor in the conceptualization and execution of these various projects.

\section{Strategies for International Educators, Faculty, and Higher Education}

Based on these two case studies, and our ongoing efforts in the areas of both campus sustainability and internationalizing the curriculum, we see a number of strategies emerging for three groups involved in these efforts: international educators and the field as a whole, faculty who lead study abroad courses, and higher education institutions.

\section{Strategies for International Educators}

International educators understand that gaining cultural awareness should not destroy the environmental climate of that culture, and thus they must act within their own offices and field to make study abroad more sustainable. Study abroad staff should consider encouraging or requiring all students who study abroad to join the Green Passport Program (Green Passport Program, 2010) or a similar program designed to give students awareness of sustainability and tools to be greener while they are abroad. They should also discuss ways to reduce one's carbon footprint abroad with students, in advising sessions and marketing materials, and in orientation and re-entry events.

Study abroad offices should also assess the carbon costs of individual programs and publish that information clearly so students can compare programs they are considering - or include carbon offsets as part of fully transparent pricing for study abroad.

To further strengthen their green efforts, study abroad staff could also consider prioritizing study abroad in locations where the human and ecological impacts of climate change are most readily apparent, or where there are notably successful practices being enacted. For the former, several possibilities would include areas where alpine glaciers and cloud forests are threatened, and lowlying coastal regions like the Netherlands or Venice that are in danger from sea 
level rise. For the latter, possibilities include locations that are the basis of our two case studies (above), as well as the cities of Curitiba, Brazil; Amsterdam, Netherlands; Copenhagen, Denmark; and Vauban, Germany (leading cities on various dimensions of sustainability practices). Even cities not quite as far along in developing sustainability and resilience policies are doing remarkable things (i.e., London, England).

A more ambitious idea would be to restrict access to study abroad programs that have too high a carbon cost or, perhaps more feasibly, involve environmental education in all study abroad programs, regardless of primary academic topic. This seems do-able since higher education professionals need not be sustainability experts in order to point out how other cultures' practices are less wasteful or how American's habits contribute to problems they observe abroad. Such a policy would raise difficult yet important questions about criteria for evaluating the necessity and educational value of particular locations as potential sites for study abroad.

Within the field of education abroad, there are several ideas that deserve serious consideration as a starting point in confronting the conundrums inherent in study abroad and climate change. First, the Forum on Education Abroad has incorporated environmental and social responsibility into its "Standards of Good Practice for Education Abroad," and NAFSA: Association of International Educators has endorsed a Special Interest Group on sustainability and is addressing this topic in a session at their annual conference in May 2011. These efforts should be robust, and other national and international organizations as well as third-party providers of study abroad should follow suit. Both the field and individual international offices must engage their staff and faculty in discussion about adopting similar standards for their programming.

As a step in this direction, we believe that a rigorous environmental rating and review of study abroad programs should become standard practice. More and more campuses are moving toward using the U.S. Green Building Council's Leadership in Energy and Environmental Design (LEED) criteria for building design. Likewise, with the growth of ecotourism, many international travel destinations are applying for and using various green certification systems, such as the Sustainable Tourism Eco-certification Program (STEP) developed by Sustainable Travel International (www.sustainabletravelinternational.org). A similar system for rating study abroad programs would help students choose programs with lower impact, and help raise awareness of best practices in study abroad offices.

Although full discussion of the meaning and usefulness of such a rating system is beyond the scope of this article, we suggest that such a system should 
consider a way for programs to get "green points" for various aspects of their planning, implementation, and follow-up. In the planning phase, criteria could include exploring destinations closer to home, potential for rail or boat travel where feasible, building in carbon offsets into the cost of the trip, institutional funding for environmentally-relevant research projects related to study abroad (as done by Middlebury College), and pre-departure briefings for students on the carbon footprint of the trip. During the program itself, study abroad experiences could be rated based on students' choice of transportation in country, amount of travel at the destination itself, choice of housing, meals, and other carbon-intensive activities (such as, say, skiing at the indoor ski slope in Dubai, as intriguing as that possibility might be). Choice of destinations and sites with particular relevance to the discussion of climate change (from a wind farm in Germany to a geothermal power plant in New Zealand to coastal areas of India threatened by rising sea levels) would likewise increase the green rating for the program. Courses, regardless of discipline, could, with a little imagination and creativity, include specific environmental or climatechange assignments (for example, a medieval history course could include an assignment comparing the carbon footprint of a medieval person and a modern day person. An English course could include reflective essays on the impact of climate change on the region visited). Post-program criteria could include factors such as on-campus presentations on the lessons learned for local and campus practices and ongoing program revision to pursue increasingly green practices. With such a system in place, study abroad staff and faculty alike could work on maximizing both the education potential and eco-rating for the trip.

Second, individuals in the field should be encouraged to design and carry out studies on how students' attitudes toward climate change and energy consumption change as a result of their study abroad experience. Work must also be done to measure and compare the impact of study abroad experiences with their carbon emission costs. By gathering and analyzing this data, we can strategically work to make the partnership between internationalization and sustainability more effective.

Third, education abroad professionals need to begin a meaningful dialogue on this issue within the field as a whole, so that policies to green study abroad are supported by the providers with which we collaborate. Without a willingness to think creatively about transportation, food choices, and energy use, a program designed in a green way by faculty and staff on campus cannot be executed that way on site. While the potential challenges for providers are abundant (higher program costs, local infrastructure that doesn't support green choices, etc.), there is hope. As students become more aware of the growing 
climate crisis, and as education abroad professionals see the importance of the partnership we suggest in this paper, providers will find a way (either within their current business models or by creating new models) to meet their clients' needs.

Some of these ideas may seem like significant deviations from conventional practices. Movements toward enacting them could call into question campus political structures and decades of established policy, will likely raise further collateral ethical conundrums, and could have financial implications that are difficult to resolve in this time of tightening budgets. But, as we have illustrated, international educators cannot continue to ignore or minimize the impact climate change is already having upon their field.

\section{Strategies for Faculty}

As the group with the closest contact with students, college and university faculty have a great deal of influence over students' academic work and potentially, in shaping a study abroad experience that inspires students to change. Faculty leading study abroad programs have the opportunity to lead discussions about the environmental impact of their courses, and how to address them. The purchase of carbon offsets is the easiest method by which faculty and their students may account for the carbon impact of their courses, and how offsets can best be used can produced informative discussions. Students can be given the responsibility of deciding which carbon offset projects should be supported for their program, which gives them a chance to fund programs they had first-hand exposure to, and emphasizes the importance of integrated projects that address not only carbon emissions and climate change, but how these issues interact with other issues such as social justice and biodiversity.

Yet we believe that offsets have drawbacks that are worthy of attention, the primary two problems being: This solution doesn't discourage energy consumption; and this solution essentially allows faculty and students to "buy" their capacity to pollute. Instead, we favor solutions where faculty encourage students to consider lifestyle changes that can prompt more sustainable choices in residential living, transportation choices, waste management, and so forth, after the travel experience is over and the class has ended. We have observed that many students returning from experiences in countries with dramatically lower levels of material wealth were changed by their experience, and had a strong desire to work toward ameliorating those conditions. Direct experience of a problem seems to motivate students to learn more about the problem and attempts to help address it. Directing this inspired energy toward sustainable choices in the future is one place where faculty can have impact.

Faculty should also consider their role on campus as it relates to study 
abroad and internationalization. They may have significant power within the college to suggest sustainable changes to internationalization efforts. Faculty who lead programs also have the opportunity to educate staff in international offices about these issues and propose/lead study abroad programs that are sustainable. Finally, faculty can influence their students in choosing sustainable semester or yearlong program options.

\section{Strategies for Higher Education}

Higher education institutions can use their position within their immediate communities, and within the larger organizational field of higher education, to take steps toward sustainability. Colleges and universities can leverage their economic power by purchasing greener alternatives to the myriad things colleges use like fertilizer, light bulbs, and paper plates. In addition, by joining national sustainability efforts like the Presidents Climate Commitment or University Leaders for a Sustainable Future, they can bring together other administrators and leaders in higher education to participate in these efforts and use the clout of their institutions to support local, regional, or national causes and affect wider change. College and university campuses can offset campus carbon emissions by establishing carbon reserves where trees could be planted and managed or engaging in local community efforts to create carbon sinks and/or generate clean, renewable energy. The type of project depends on the institutions' location, size, and economic situation; some urban campuses (like ours) are better suited to community partnerships, while others with more available real estate nearby can host a carbon reserve or wind farm. These kinds of projects offer educational opportunities for students, as well as create opportunities for partnership with the community and local businesses.

Institutions of higher education can initiate discussions around possible policy shifts around sustainable campuses and sustainable international education, particularly if there isn't strong drive in this direction from within the international office, among faculty who lead study abroad, or among students on their campus. At our institution, for example, student activists have been a driving force for change around sustainability, but other institutions may have other power centers.

In addition, colleges and universities can advocate for a nationwide partnership among green technology research projects at colleges \& universities to solve carbon problems. These efforts can highlight individual college's research and technology projects, attracting good press and possibly funding. These projects have an added benefit of being an 'in house' solution to problems of carbon emissions on campus, including study abroad programs. Also, colleges and universities can advocate on a federal, state and local level 
to create policies that reflect the real cost of carbon emissions, either a tax, or removing subsidies, or cap and trade systems.

At some point in the future, when our national and global societies have transitioned to post-carbon economies and developed new ways to fuel international travel, perhaps the issue raised in this paper - the apparent contraction between study abroad and environmental sustainability - will be irrelevant. But in the meantime, with the specter of widespread climatic disasters already upon us, study abroad professionals, faculty, and higher education have to think very carefully about how, where, and why we study abroad. We argue that we must do everything we can to reduce our carbon footprint while still providing students with the extraordinary learning they can only get from directly experiencing the world. Study abroad and sustainability indeed have a necessary partnership.

\section{Acknowledgments}

The authors thank the Editors, reviewers, and Professor John Harkness for critical insights and suggestions for improving the paper. The "Sustainable Cities in North America" course was supported with a Understanding Canada -- Canadian Studies Program Faculty Enrichment Grant provided by the Government of Canada/avec l'appui du gouvernement du Canada.

\section{Notes}

${ }^{1}$ Interview with Dr. Howard Laren, Senior Operator-Climate Change, Ministry for the Environment, May 18, 2009, Wellington, NZ. See also http://www.mfe.govt.nz/issues/climate/about/impacts.html

${ }^{2}$ Presentation and interview with Cath Wallace, University of Victoria, Wellington, NZ, May 15, 2009.

\section{References}

Association of University Leaders for a Sustainable Future. 2008. Tallories Declaration. http://www.ulsf.org/talloires declaration.html. Accessed February 20, 2010.

Bowers, C. A. 1997. The Culture of Denial: Why the Environmental

Movement Needs a Strategy for Reforming Universities and Public Schools.

Albany, N.Y.: SUNY Press.

Creighton, Sarah. 1998. Greening the Ivory Tower: Improving the

Environmental Track Record of Universities, Colleges, and other

Institutions. Cambridge, MA: MIT Press.

Dewey, John. 1938. Experience and Education. New York: Touchstone.

Durie, Mason. 1998. Te Mana, Te Kawanatanga: The Politics of Maori Self- 
Determination. Oxford University Press.

Green Passport Program. 2010. http://www.greenpassport.us/. Accessed February 21, 2010.

Gruenewald, David. 2008. "The Best of Both Worlds: A Critical Pedagogy of Place.” Environmental Education Research. Vol. 14, No. 3, 308-324.

Hanson, James, Makiko Sato, Pushker Kharecha, David Beerling, Robert Berner,

Valerie Masson-Delmotte, Mark Pagani, Maureen Raymo, Dana L. Royer, and James C. Zachos. 2008. "Target Atmospheric $\mathrm{CO}_{2}$ : Where Should Humanity Aim?” http://arxiv.org/ftp/arxiv/papers/0804/0804.1126.pdf. Accessed February 19, 2010.

Keniry, Julian. 1995. Ecodemia: Campus Environmental Stewardship at the Turn of the 21st Century. Washington, D.C.: National Wildlife Federation.

McKibben, Bill. 2007. Deep Economy: The Wealth of Communities and the Durable Future. New York: Henry Holt and Company.

Mumford, Lewis. 1934. Technics and Civilization. New York: Harcourt Press.

NAFSA: Association of International Educators. 1998-2009. Reports on Campus Internationalization. Resource Library. http://www.nafsa.org/ knowledge_community_network.sec/international_education_4/chief_ international_education/practice_resources_14/internationalizing_the/ ace_internationalization/. Accessed February 20, 2010.

Pollan, Michael. 2006. The Omnivore's Dilemma: A Natural History of Four Meals. New York: The Penguin Press HC.

Presidents' Climate Commitment. 2007-2009. Text of the American College \& University Presidents' Climate Commitment. http://www. presidentsclimatecommitment.org/about/commitment. Accessed February 19, 2010.

Singer, Peter. 2004. One World: The Ethics of Globalization. $2^{\text {nd }}$ Ed. New Haven, CT: Yale University Press.

Sobel, D. 1996. Beyond Ecophobia: Reclaiming the Heart in Nature Education. Great Barrington, MA: The Orion Society and The Myrin Institute Society for College and University Planning. 2009. Campus Sustainability Planning Network. http://www.campussustainability.info/.

TerraPass. http://www.terrapass.com. Accessed February 19, 2010. The Forum on Education Abroad. 2009. Draft of Environmental and Social Responsibility Additions to the Standards of Good Practice. http://www. forumea.org/documents/StandardsDraftRevisionsEnvir-SocRespons.pdf. Accessed February 20, 2010. 
Andrea M.W. Dvorak, Lars D. Christiansen, Nancy L. Fischer, Joseph B. Underhill

Wackernagel, Mathis and W. Rees. 1996. Our Ecological Footprint: Reducing Human Impact on the Earth. Gabriola Island, BC: New Society Publishers. 